\title{
Growth and Accumulation of Solutes by Phytophthora cinnamomi and Other Lower Fungi in Response to Changes in External Osmotic Potential
}

\author{
By ELIZABETH J. LUARD \\ Department of Forestry, Australian National University, P.O. Box 4, Canberra, A.C.T. 2600, \\ Australia
}

(Received 30 October 1981; revised 4 May 1982)

\begin{abstract}
Proline and the solute used to control the osmotic potential of the medium, either sucrose or $\mathrm{KCl}$, accumulated in the hyphae of Phytophthora cinnamomi as the steady state external potential decreased. Proline also accumulated in three other lower fungi. Very little polyol was detected in any of the species analysed. Proline was lost following hypoosmotic shock and accumulated after hyperosmotic shock in $P$. cinnamomi. The time taken for growth to resume after shock treatment was variable, but less than $5 \mathrm{~h}$. Potassium was the predominant cation in hyphae grown on sucrose but chloride was insufficient to maintain electroneutrality. The potassium to sodium ratio followed a similar pattern to the radial growth rate with respect to external potential, with maxima at a potential slightly below the highest potential tested. When the osmoticum was sucrose, the calculated internal potential was $20 \%$ greater than the observed osmotic potential, but when the osmoticum was $\mathrm{KCl}$, the calculated potential was too high by a factor of more than two, probably indicating error in assumptions concerning the location of ions within the hyphae.
\end{abstract}

\section{INTRODUCTION}

Two Fungi Imperfecti tolerant of low water potential were found to accumulate both glycerol and the osmoticum used in the medium under both steady state conditions and following osmotic shock (Luard, 1982a, b). In order to establish whether this mechanism of osmoregulation was also common to fungi less tolerant of water stress, Phytophthora cinnamomi Rands, a member of the Oomycetes, and three other lower fungi were analysed following similar treatment. Phytophthora cinnamomi is not considered to be tolerant of low water potential (Luard \& Griffin, 1981).

\section{METHODS}

Fungi and media. Phytophthora cinnamomi mating type A2 (isolate 176) was obtained from the culture collection of the Forestry Department, Australian National University and maintained on V-8 agar. A water mould (Saprolegniaceae) was isolated from Sullivan's Creek, Australian National University, by baiting diluted creek water with millet seed. Mucor hiemalis Wehmer and Pythium debaryanum Hesse were obtained from the Botany Department, Australian National University. These last three were maintained in culture on $1.7 \%$ cornmeal agar.

The growth medium used throughout was Czapek-Dox agar to which $5 \mathrm{~g}$ Difco yeast extract $\mathrm{l}^{-1}$ had been added (CYA). Water potential was controlled osmotically by the addition of either sucrose or $\mathrm{KCl}$ to the medium (Luard \& Griffin, 1981). The osmotic potential of unsupplemented CYA was $-0.56 \mathrm{MPa}$. For convenience the theoretical potential of the added solute has been referred to throughout and designated by the symbol $\psi_{\mathrm{s}}$. The true potential would be close to $0.56 \mathrm{MPa}$ less than $\psi_{\mathrm{s}}$.

Plastic Petri dishes ( $9 \mathrm{~cm}$ diam.) containing $30 \mathrm{ml}$ medium were used in both steady state and osmotic shock experiments. All plates were overlaid with cellophane and inoculated centrally with a $4 \mathrm{~mm}$ diameter plug cut from the margin of a colony whose growth rate was linear. Plates were stored in plastic bags and incubated at $25^{\circ} \mathrm{C}$.

Colonies from the steady state experiments were analysed when a radius of $20 \mathrm{~mm}$ was reached. Osmotic shock was applied to colonies of $20 \mathrm{~mm}$ radius by lifting the cellophane with the colony from the surface of the agar on 
which it had grown and laying it on the agar of a fresh plate of the desired potential. Analyses of the hyphae were made at intervals following each transfer. In a separate series of experiments, growth of hyphae after osmotic shock was followed using small colonies grown on Petrislides (Millipore) which could be observed directly under the microscope (Luard, 1982b).

Analysis of hyphae. Analyses were performed as described by Luard (1982a). Briefly, water content was obtained from oven dry weight, osmotic potential by thermocouple psychrometry, cations by atomic absorption spectroscopy, chloride by titration, amino acids by automated ion exchange, and ethanol-soluble sugars and polyols by GLC of trimethylsilyl derivatives.

\section{RESULTS}

\section{Hyphal osmotic potential and water content}

Hyphal osmotic potentials of $P$. cinnamomi decreased as the steady state potential of the medium decreased and positive turgor was maintained, the values being similar whether the osmoticum was sucrose or $\mathrm{KCl}$ (Fig. 1). The water content also decreased as the osmotic

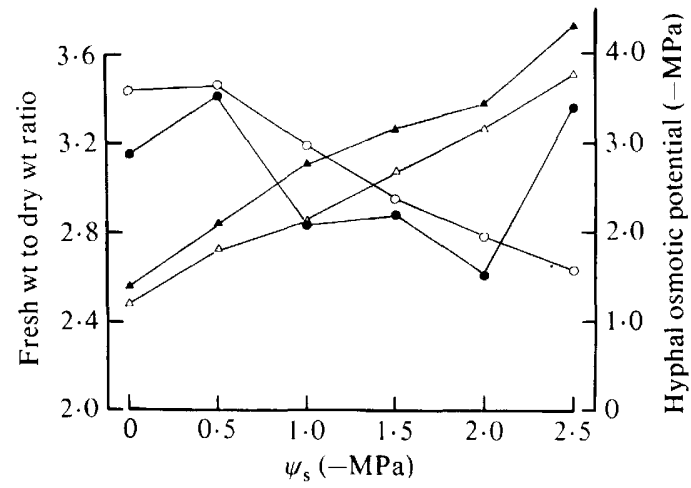

Fig. 1

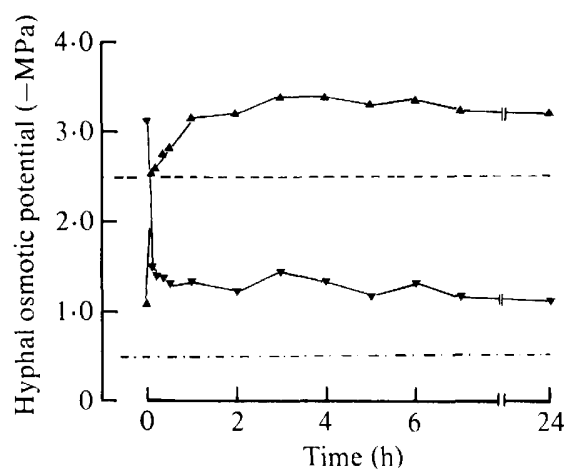

Fig. 2

Fig. 1. Effect of external osmotic potential on the fresh weight to dry weight ratio $(O, O)$ and hyphal osmotic potential ( $\triangle$, $\boldsymbol{\Lambda}$ ) of colonies ( $20 \mathrm{~mm}$ radius) of Phytophthora cinnamomi grown on sucrose (open symbols) and $\mathrm{KCl}$ (closed symbols).

Fig. 2. Effect of osmotic shock on the hyphal osmotic potential of Phytophthora cinnamomi. Hypoosmotic shock $(\boldsymbol{\nabla})$ and hyperosmotic shock $(\boldsymbol{\Delta})$. Broken lines indicate true external potential of shock treatment.



Fig. 3. Effect of osmotic potential on the potassium to sodium ratio $(O)$ and the radial growth rate $(\square)$ of Phytophthora cinnamomi grown on sucrose osmotica. 
Table 1. Ion content of Phytophthora cinnamomi grown at different osmotic potentials produced by the addition of sucrose

\begin{tabular}{cccccc}
\multicolumn{5}{c}{ Values are means \pm standard deviations of three samples. } \\
$\begin{array}{c}\psi_{\mathrm{s}} \\
\mathrm{MPa})\end{array}$ & $\mathrm{K}^{+}$ & $\mathrm{Na}^{+}$ & $\mathrm{Mg}^{2+}$ & $\mathrm{Ca}^{2+}$ & $\mathrm{Cl}^{-}$ \\
0 & $368 \pm 19$ & $105 \pm 3$ & $23 \pm 2$ & $3 \pm 1$ & $73 \pm 16$ \\
$0 \cdot 5$ & $304 \pm 29$ & $82 \pm 3$ & $19 \pm 1$ & $3 \pm 1$ & $83 \pm 6$ \\
$1 \cdot 0$ & $303 \pm 5$ & $111 \pm 20$ & $19 \pm 1$ & $1 \pm 1$ & $82 \pm 12$ \\
$1 \cdot 5$ & $186 \pm 0$ & $75 \pm 1$ & $12 \pm 2$ & $1 \pm 1$ & $58 \pm 5$ \\
$2 \cdot 0$ & $220 \pm 20$ & $107 \pm 10$ & $14 \pm 1$ & $1 \pm 0$ & $69 \pm 5$ \\
$2 \cdot 5$ & $240 \pm 26$ & $112 \pm 2$ & $15 \pm 2$ & $1 \pm 0$ & $81 \pm 4$
\end{tabular}

Table 2. Effect of osmotic potential on the ethanol soluble sugar, polyol and total amino acid other than proline content of Phytophthora cinnamomi

\begin{tabular}{|c|c|c|c|c|c|c|c|}
\hline \multirow{3}{*}{$\begin{array}{c}\psi_{\mathrm{s}} \\
(-\mathrm{MPa})\end{array}$} & \multicolumn{7}{|c|}{ Solute content $\left[\mu \mathrm{mol}(\mathrm{g} \text { dry } w t)^{-1}\right]$} \\
\hline & \multicolumn{4}{|c|}{ Sucrose osmoticum } & \multicolumn{3}{|c|}{$\mathrm{KCl}$ osmoticum } \\
\hline & Sucrose & Glucose & Arabitol & TAA* $^{*}$ & Glucose & Arabitol & TAA* \\
\hline 0 & 0 & 41 & 24 & 71 & 23 & $\operatorname{tr}$ & 83 \\
\hline 0.5 & 375 & 23 & $\operatorname{tr}$ & 54 & 39 & 11 & 79 \\
\hline 1.0 & 389 & 84 & 18 & 73 & 44 & 13 & 88 \\
\hline $1 \cdot 5$ & 366 & 29 & 11 & 56 & 28 & tr & 83 \\
\hline $2 \cdot 0$ & 344 & 50 & 14 & 85 & 17 & $\mathrm{tr}$ & 64 \\
\hline $2 \cdot 5$ & 409 & 15 & tr & 65 & 53 & 12 & 77 \\
\hline
\end{tabular}

potential fell. The rather erratic values of the $\mathrm{KCl}$ series probably reflect the very low dry weight production on this medium. Following hypoosmotic shock from $-2 \mathrm{MPa} \mathrm{KCl}$ to $0 \mathrm{MPa}$, and hyperosmotic shock of the reverse conditions, hyphal osmotic potential showed rapid adjustment (Fig. 2) which was also reflected in the change in fresh weight to dry weight ratio.

\section{Ions}

The ion content of $P$. cinnamomi grown under steady state conditions with an osmoticum of sucrose is shown in Table 1 . The potassium content decreased as the external potential decreased, but the $\mathrm{Na}^{+}$content showed no definite relationship. However, the $\mathrm{K}^{+}: \mathrm{Na}^{+}$ratio which is shown with the radial growth rate in Fig. 3 resembled the pattern observed for Penicillium chrysogenum rather than Chrysosporium fastidium, with a maximum at a potential slightly below the highest tested (Luard, 1982a).

When a $\mathrm{KCl}$ osmoticum was used under steady state conditions, $\mathrm{K}^{+}$and $\mathrm{Cl}^{-}$both accumulated in proportion to the concentration in the medium, the amounts of the latter being somewhat lower (Fig. 4a). Similarly, these ions were lost following hypoosmotic transfer from $-2 \mathrm{MPa} \mathrm{KCl}$ to $0 \mathrm{MPa}$ and taken up after hyperosmotic transfer in the reverse direction (Fig. $4 b, c) . \mathrm{Na}^{+}$remained at a low level in all experiments.

Sugars and polyols

Sucrose was the principal sugar detected in P. cinnamomi when the osmoticum was sucrose (Table 2), but the relationship between internal and external sucrose was not linear. The glucose content was similar in this species whether the osmoticum was $\mathrm{KCl}$ or sucrose. The only polyol detected was arabitol, and this at extremely low levels. 

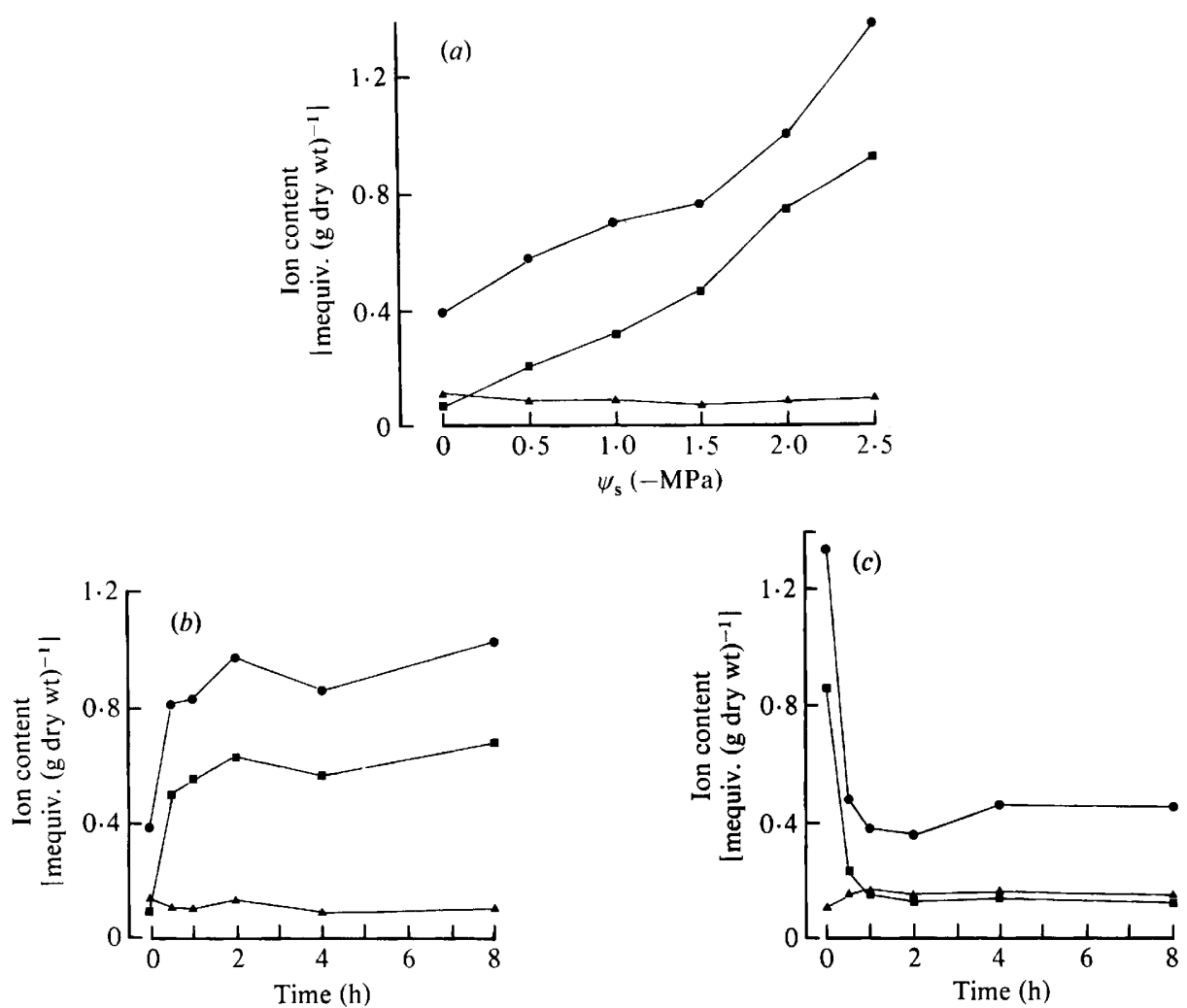

Fig. 4. Effect of steady state osmotic potential (a), hyperosmotic shock $(b)$ and hypoosmotic shock $(c)$ on the potassium (O), sodium $(\boldsymbol{\Lambda})$ and chloride $(\boldsymbol{D})$ content of Phytophthora cinnamomi grown on $\mathrm{KCl}$.
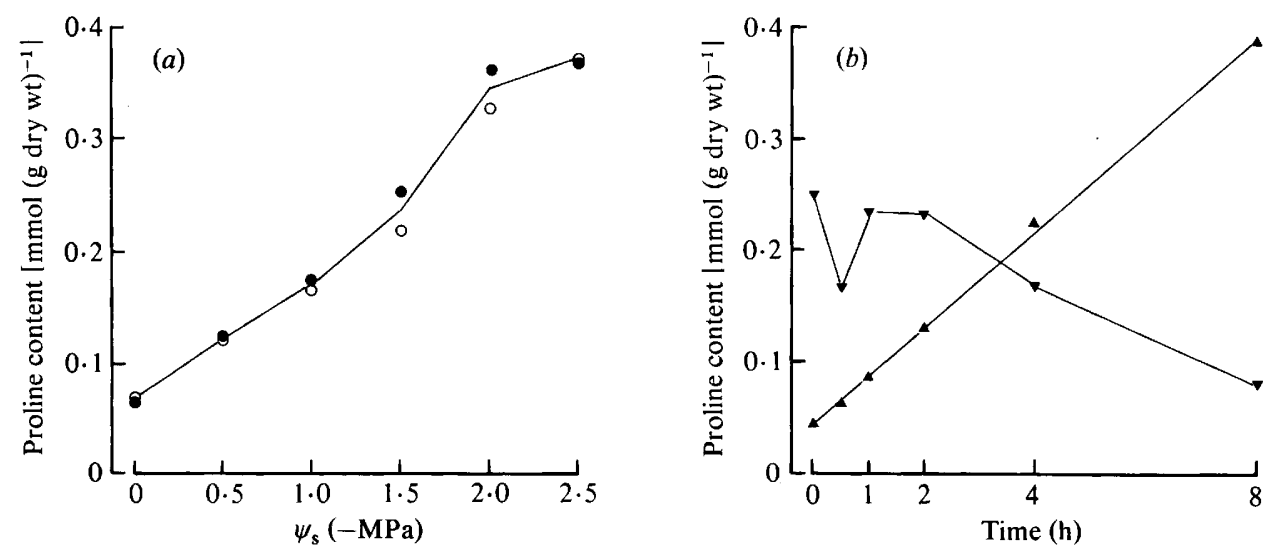

Fig. 5. Effect of steady state osmotic potential $(a)$ and osmotic shock $(b)$ on the proline content of Phytophthora cinnamomi grown on sucrose osmoticum (open symbols) and on $\mathrm{KCl}$ osmoticum (closed symbols). Hyperosmotic shock $(\boldsymbol{\Lambda})$ and hypoosmotic shock $(\nabla)$.

\section{Amino acids}

The amino acid proline increased in $P$. cinnamomi as the water potential was reduced. The amounts of proline were almost identical whether the osmoticum was $\mathrm{KCl}$ or sucrose (Fig. 5).

The accumulation and loss of proline by $P$. cinnamoni after hyperosmotic and hypoosmotic 
Table 3. Effect of osmotic potential on some organic solutes of three lower fungi

\begin{tabular}{|c|c|c|c|c|c|c|c|c|c|}
\hline \multirow[b]{2}{*}{ Species } & \multirow[b]{2}{*}{$\psi_{s}(-M P a)$} & \multicolumn{8}{|c|}{ Solute content $\left[\mu \mathrm{mol}(\mathrm{g} \text { dry } w \mathrm{t})^{-1}\right]$} \\
\hline & & 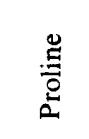 & 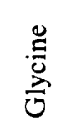 & 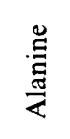 & 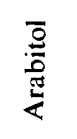 & $\stackrel{\mathscr{O}}{\stackrel{\mathscr{E}}{E}}$ & $\begin{array}{l}0 \\
\stackrel{0}{0} \\
\stackrel{0}{0}\end{array}$ & 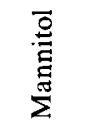 & 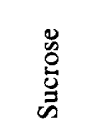 \\
\hline Mucor hiemalis & $\begin{array}{l}0 \\
0.5 \\
1.5\end{array}$ & $\begin{array}{l}15 \cdot 1 \\
59 \cdot 3 \\
91 \cdot 0\end{array}$ & $\begin{array}{r}8.0 \\
11 \cdot 4 \\
9 \cdot 3\end{array}$ & $\begin{array}{l}32.7 \\
78.9 \\
77 \cdot 2\end{array}$ & $\begin{array}{l}0 \\
0 \\
0\end{array}$ & $\begin{array}{l}0 \\
0 \\
0\end{array}$ & $\begin{array}{l}\text { tr } \\
\text { tr } \\
\text { tr }\end{array}$ & $\begin{array}{l}0 \\
0 \\
0\end{array}$ & $\begin{array}{c}\mathrm{tr} \\
80 \cdot 1 \\
333 \cdot 1\end{array}$ \\
\hline Pythium debaryanum & $\begin{array}{l}0 \\
0.5 \\
1.5\end{array}$ & $\begin{array}{r}15.3 \\
186.6 \\
56.2\end{array}$ & $\begin{array}{r}4.9 \\
10 \cdot 3 \\
3 \cdot 4\end{array}$ & $\begin{array}{l}11 \cdot 7 \\
30 \cdot 8 \\
20 \cdot 3\end{array}$ & $\begin{array}{c}0 \\
\operatorname{tr} \\
26 \cdot 4\end{array}$ & $\begin{array}{c}\operatorname{tr} \\
193 \cdot 0 \\
790 \cdot 4\end{array}$ & $\begin{array}{c}\operatorname{tr} \\
280 \cdot 0 \\
912 \cdot 6\end{array}$ & $\begin{array}{c}0 \\
\mathrm{tr} \\
135 \cdot 0\end{array}$ & $\begin{array}{c}0 \\
53 \cdot 9 \\
58 \cdot 9\end{array}$ \\
\hline Unidentified water mould & $\begin{array}{l}0 \\
0.5 \\
1.5\end{array}$ & $\begin{array}{r}23 \cdot 1 \\
67 \cdot 5 \\
156 \cdot 3\end{array}$ & $\begin{array}{l}6 \cdot 7 \\
7 \cdot 1 \\
4 \cdot 2\end{array}$ & $\begin{array}{l}19 \cdot 0 \\
23 \cdot 0 \\
19 \cdot 8\end{array}$ & $\begin{array}{l}0 \\
0 \\
0\end{array}$ & $\begin{array}{l}0 \\
\text { tr } \\
\text { tr }\end{array}$ & $\begin{array}{c}0 \\
\operatorname{tr} \\
48.9\end{array}$ & $\begin{array}{l}0 \\
\text { tr } \\
\text { tr }\end{array}$ & $\begin{array}{c}0 \\
160.9 \\
410.5\end{array}$ \\
\hline
\end{tabular}

shock are also shown in Fig. 5. Accumulation appeared to be linear with time, the content after $8 \mathrm{~h}$ being somewhat higher than the steady state level reported, or of the initial value for the hypoosmotic shock treatment. Loss of proline was relatively slow, suggesting metabolic conversion rather than leakage.

The total amino acid pools other than proline were of a similar order in P. cinnamomi (Table 2) and Penicillium chrysogenum and at least four times greater than the $C$. fastidium pool (Luard, $1982 a$ ) when equivalent potentials are compared. Glycine and alanine were the other predominant components of the pool but showed no obvious relationship to external potential.

\section{Other lower fung $i$}

Mucor hiemalis, Pythium debaryanum and the water mould all accumulated proline as the osmotic potential decreased, although amounts were lower than those found in $P$. cinnamomi at equivalent potentials (Table 3, Fig. 5). The lowest potential, $-1.5 \mathrm{MPa}$, was very close to the growth limit of Pythium debaryanum and colonies were extremely sparse, thus the values from this treatment may not have been accurate. Glycine and alanine were the other predominant components of the amino acid pool. There were some species differences in that $M$. hiemalis and the water mould contained only sucrose, whereas in Pythium debaryanum sucrose had obviously been hydrolysed to the constituent monosaccharides. Mannitol and arabitol were detected only in Pythium debaryanum and none of the three appeared to contain glycerol.

\section{Growth following osmotic shock}

Phytophthora cinnamomi was subjected to hyperosmotic shock from 0 to $-2 \mathrm{MPa}$ sucrose. Sometimes the tip started to regrow within $1 \mathrm{~h}$. Alternatively, the tip did not regrow, but growth eventually resumed in the first primary lateral behind the leading hypha, this took $5 \mathrm{~h}$. In both cases the new growth rate was close to the steady state growth rate for $-2 \mathrm{MPa}$ colonies.

Following hypoosmotic shock from $-2 \mathrm{MPa}$ to $0 \mathrm{MPa}$, the pattern of regrowth was also variable. If bursting did not occur, regrowth started from the tip after about $1 \mathrm{~h}$ but with a different orientation, and was followed by considerable lateral branching. On other occasions, there was extensive bursting. The burst tips clearly did not recover and growth recommenced after about $3 \mathrm{~h}$ at branches behind the second or third lateral; that is 100 to $200 \mu \mathrm{m}$ behind the apex.

\section{DISCUSSION}

The solutes measured in two Fungi Imperfecti largely underestimated the observed osmotic potential of the hyphae (Luard, 1982a). An attempt has also been made to calculate hyphal 
Table 4. Estimated concentrations and osmotic potentials of some hyphal solutes in Phytophthora cinnamomi

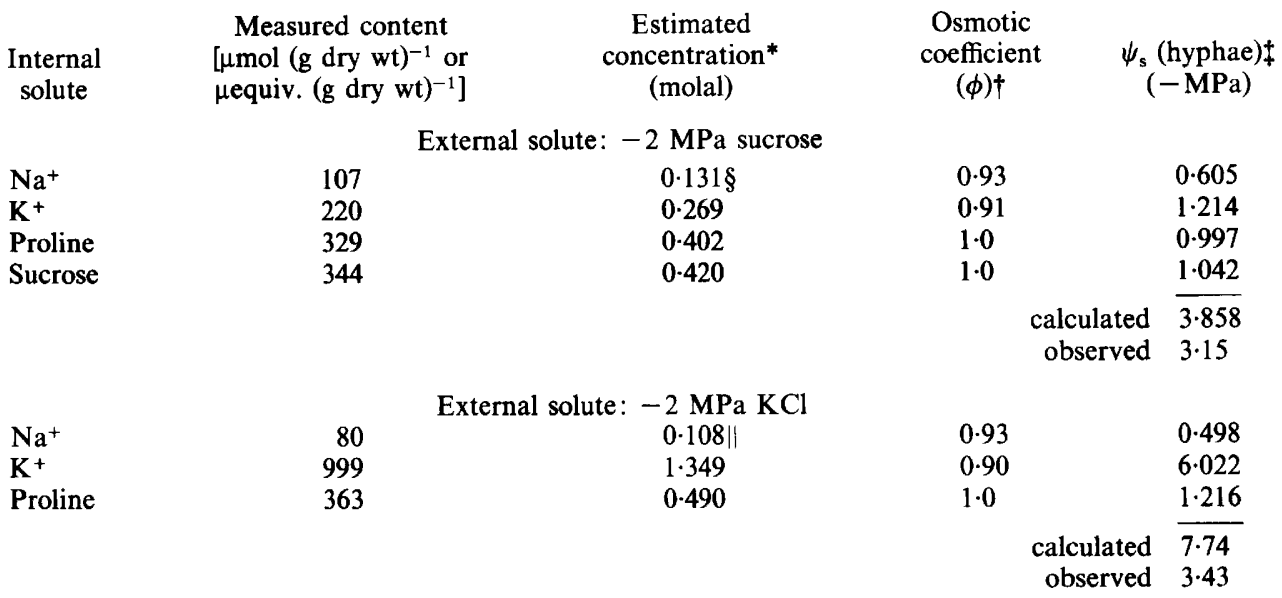

* For the purpose of the calculation, cations were assumed to be totally balanced by $\mathrm{Cl}^{-}$, as insufficient anions were measured.

$\dagger \mathrm{NaCl}, \mathrm{KCl}$ and sucrose from Robinson \& Stokes (1955); proline is assumed equal to 1.0.

$\ddagger$ Calculated from the relationship $\psi_{\mathrm{s}}=-\boldsymbol{R} T m v \phi \rho$ where $\boldsymbol{R}$ is the gas constant, $\bar{T}$ the temperature (K), $v$ the number of ions per molecule, $m$ the molality, and $\rho$ the density of water.

$\S$ Calculated from fresh wt:dry wt $2 \cdot 78$, wall water $29 \%$ and non-solvent cytoplasmic water $25 \%$.

|| Calculated from fresh wt:dry wt $2 \cdot 61$, wall water $29 \%$ and non-solvent cytoplasmic water $25 \%$.

potentials for $P$. cinnamomi under steady state conditions (Table 4). Concentrations of the major solutes have been estimated using the measured water content with corrections for non-solvent water in the walls as determined by electron microscopy (Luard, 1980) and $25 \%$ of the cytoplasmic water also being unavailable as a solvent (Cooke \& Kuntz, 1974; Griffin, 1981). At an external potential of $-2 \mathrm{MPa}$, when the osmoticum was sucrose, there was an overestimation of about $0.7 \mathrm{MPa}$ in the calculated value relative to the observed potential. However, in the case of the $\mathrm{KCl}$ osmoticum, the overestimation was greater than two times. As discussed by Luard (1982a) the assumptions concerning osmotic volume may not be correct. The electron micrographs, which were of material grown on sucrose, were interpreted as indicating a considerable thickening of the cell wall in $P$. cinnamomi. The volume of the cell occupied by the wall appeared to increase from $16 \%$ at $0 \mathrm{MPa}$ to $40 \%$ at $-3 \mathrm{MPa}$. If, however, this interpretation was incorrect, or not applicable to hyphae grown on $\mathrm{KCl}$, the potential due to internal $\mathrm{K}^{+}$, if the wall constituted $16 \%$ of the cell volume, would be reduced to $-4.7 \mathrm{MPa}$. Since this figure is still a considerable overestimate of the observed potential, some other explanation must be sought. The assumption that cations are completely located in the cytoplasm may be incorrect. If a proportion of the $\mathrm{K}^{+}$was associated with the wall as fixed charges, such an error would have been magnified by the apparently very thick walls of $P$. cinnamomi at low potentials. Also, in the calculation $\mathrm{K}^{+}$was assumed to be totally balanced by $\mathrm{Cl}^{-}$and $\mathrm{KCl}$ solutions have an osmotic coefficient close to $1 \cdot 0$. Other potassium salts may be less osmotically effective. Furthermore, there may have been some contamination from the external medium, despite the blotting procedure used.

Proline appears to replace glycerol as the principal solute involved in osmotic adjustment in these lower fungi. Proline also increased following hyperosmotic shock and decreased after hypoosmotic shock in $P$. cinnamomi (Fig. 5), confirming its role in osmotic adjustment in this species. Proline accumulates in response to water stress in higher plants, particularly the Chenopodiaceae and Gramineae (e.g. Chu et al., 1976; Storey \& Wyn Jones, 1977), in bacteria (e.g. Christian \& Hall, 1972; Measures, 1975) and in algae (e.g. Liu \& Hellebust, 1976; Brown \& 
Hellebust, 1978), but there is apparently no previous record of its accumulation in fungi. The green alga Stichococcus bacillaris is of interest in that it accumulates both a polyol (sorbitol) and an amino acid (proline) (Brown \& Hellebust, 1978). Some species of Mucor may produce glycerol as well as proline.

Polyols are uncommon, although not totally absent from the lower fungi. Pfyffer \& Rast (1980) reported that polyols were absent from $P$. cinnamomi but small amounts of arabitol were found in the present experiment (Table 1). Glycerol was not detected in the lower fungi analysed here, but twenty-three species of Mucor accumulated large amounts of glycerol when stimulated by the addition of $\mathrm{NaHSO}_{3}$ or $\mathrm{Na}_{2} \mathrm{CO}_{3}$ at optimum concentrations of $6 \%(\mathrm{w} / \mathrm{v})$ and $4 \%(\mathrm{w} / \mathrm{v})$, respectively (about -4.0 and $-2.9 \mathrm{MPa}$ ) (Takahashi \& Asai, 1933). A number of Mucor species are known to accumulate mannitol, although $M$. hiemalis was not among those tested (Boonsaeng et al., 1976). The absence of a pentitol in M. hiemalis agrees with the results of Curtis et al. (1980) who found arabitol to be present in a number of Mucorales but not in this species. Pythium spp. were not included in the survey of Pfyffer \& Rast (1980) and their report of the absence of a pentitol in $P$. cinnamomi may have resulted from the different growth conditions.

Mucor hiemalis was the most xerotolerant of the four lower fungi tested here, and this was consistent with the survey of Tresner \& Hayes (1971) on the $\mathrm{NaCl}$ tolerance of fungi. The Saprolegniaceae are probably the least tolerant, and have not been found in estuaries with a salinity of greater than $2.8 \%(-0.01 \mathrm{MPa})$ although higher salinities were tolerated in culture (Te Strake, 1959).

That lower fungi should differ from other fungi in their mode of osmoregulation is not surprising. The dependence, at least of the zoosporic fungi, on an aquatic reproductive form suggests that their evolutionary origins are different from other fungi, and they also differ physiologically. It would be of interest to determine whether more natural substrates than those employed here, and in particular whether variation in the $\mathrm{C}: \mathrm{N}$ ratio, which is likely to be much higher in the natural organic substrates of these fungi, alters either quantitatively or qualitatively the solutes involved in osmotic adjustment. It should be remembered that the zoosporic lower fungi at least, because of their aquatic asexual stage, are limited to habitats of extremely high water potentials in nature (Duniway, 1979). This characteristic is more likely to limit survival than an ability for vegetative growth at the relatively low potentials used in this work.

I am grateful to Ms K. Britt for the amino acid analyses and to Mrs P. Abonyi and Mr F. Darlington for the atomic absorption spectroscopy. I thank Professor D. Griffin for critically reading the manuscript. This work was carried out during the tenure of a Commonwealth Postgraduate Award.

\section{REFERENCES}

Boonsaeng, V., Sullivan, P. A. \& Shepherd, M. G. (1976). Mannitol production in fungi during glucose catabolism. Canadian Journal of Microbiology 22, 808-816.

Brown, L. M. \& Hellebust, J. A. (1978). Sorbitol and proline as intracellular osmotic solutes in the green alga Stichococcus bacillaris. Canadian Journal of Botany 56, 676-679.

Christian, J. H. B. \& Hall, J. M. (1972). Water relations of Salmonella oranienburg : accumulation of potassium and amino acids during respiration. Journal of General Microbiology 70, 497-506.

Chu, T. M., Aspinall, D. \& Paleg, L. G. (1976). Stress metabolism. VIII. Specific ion effects on proline accumulation in barley. Australian Journal of Plant Physiology 3, 503-511.

COOKE, R. \& KUNTZ, I. D. (1974). The properties of water in biological systems. Annual Review of Biophysics and Bioengineering 3, 95-126.

Curtis, F. C., Lewis, D. H. \& Cooke, R. C. (1980). Distribution of a pentitol in Mucorales. Transactions of the British Mycological Society 74, 421-423.

DUNIWAY, J. M. (1979). Water relations of water molds. Annual Review of Phytopathology 17, 431460.

GRIFFIN, D. M. (1981). Water and microbial stress. Advances in Microbial Ecology 5, 91-136.

LiU, M. S. \& Hellebust, J. A. (1976). Effects of salinity and osmolarity of the medium on amino acid metabolism in Cyclotella cryptica. Canadian Journal of Botany 54, 938-948.

LUARD, E. J. (1980). Water relations of fungi with particular reference to xerophytic species. Ph.D. thesis, Australian National University.

LUARD, E. J. (1982a). Accumulation of intracellular solutes by two filamentous fungi in response to growth at low steady state osmotic potential. Journal of General Microbiology 128, 2563-2574. 
LUARD, E. J. (1982b). Effect of osmotic shock on some intracellular solutes in two filamentous fungi. Journal of General Microbiology 128, 2575-2581.

LUARD, E. J. \& GRIFFIN, D. M. (1981). Effect of water potential on fungal growth and turgor. Transactions of the British Mycological Society 76, 33-40.

Measures, J. C. (1975). Role of amino acids in osmoregulation of non-halophilic bacteria. Nature, London 257, 398-400.

PfyfFer, G. E. \& RAST, D. M. (1980). The polyol pattern of some fungi not hitherto investigated for sugar alcohols. Experimental Mycology 4, 160-170.

RoBinson, R. A. \& StOKes, R. H. (1955). Electrolyte Solutions. New York: Academic Press.
Storey, R. \& WYN Jones, R. G. (1977). Quarternary ammonium compounds in plants in relation to salt resistance. Phytochemistry 16, 447-453.

TaKaHashi, T. \& Asai, T. (1933). Fermentation products of Mucor. III. Production of glycerol and the effect of the addition of $\mathrm{NaHSO}_{3}$ and $\mathrm{Na}_{2} \mathrm{CO}_{3}$. Journal of the Agricultural Chemical Society of Japan 9 , 443-448.

Te Strake, D. (1959). Estuarine distribution and saline tolerance of some Saprolegniaceae. Phyton 12, 147152.

Tresner, H. D. \& Hayes, J. A. (1971). Sodium chloride tolerance of terrestrial fungi. Applied Microbiology 22, 210-213. 